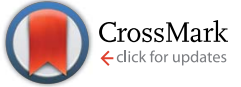

Cite this: RSC Adv., 2017, 7, 10333

Received 22nd November 2016 Accepted 5th January 2017

DOI: $10.1039 / c 6 r a 27114 f$

rsc.li/rsc-advances

\section{Novel multi-responsive polymer magnetic microgels with folate or methyltetrahydrofolate ligand as anticancer drug carriers}

\begin{abstract}
Yunli Hu, ${ }^{a}$ Weijun Liu ${ }^{b}$ and Fanhong Wu*ab
Folate-or L-5-methyltetrahydrofolate-modified poly(ethyleneimine) (PEI) functionalized magnetic microgels (MP-PNAAEF or MP-PNAAEM) for targeted delivery to positive folate-receptor [FR(+)] cancer cells have been successfully prepared. Transmission electron microscopy (TEM) shows that the $\mathrm{Fe}_{3} \mathrm{O}_{4}$ nanoparticles are well covered with PNAAEF microgels, exhibiting regular spherical structures with few agglomerates. The mean size of the magnetic microgels measured by dynamic light scattering (DLS) is dependent on temperature and $\mathrm{pH}$, and they exhibit good thermosensitivity as well as $\mathrm{pH}$ sensitivity. The research on drug loading and the drug release behavior of magnetic microgels shows that the MPPNAAEF and MP-PNAAEM microgels are capable of loading more doxorubicin hydrochloride (DOX) than MP-PNAAE under appropriate conditions, and in vitro release is faster at $\mathrm{pH} 4.5$ than at $\mathrm{pH} 7.4$, and faster at $45^{\circ} \mathrm{C}$ than at $37^{\circ} \mathrm{C}$. In vitro cytotoxicity of these microgels to Hela cells [FR(+)] and L02 cells [FR(-)] were evaluated, and all microgels were nontoxic up to a concentration of $15 \mu \mathrm{g} \mathrm{mL}^{-1}$ toward Hela cells and $30 \mu \mathrm{g} \mathrm{mL} \mathrm{m}^{-1}$ toward L02 cells. Specifically, the cellular uptake of MP-PNAAE, MP-PNAAEF and MPPNAAEM was observed with both cell lines. FA and MTHF modification on the MP-PNAAE increased the microgel uptake by Hela cells, but not by the L02 cells, as demonstrated by fluorescence microscopy; thus, the MTHF may possess remarkable properties toward Hela cells. Meanwhile, the DOX-loaded MPPNAAEF and MP-PNAAEM microgels present greater cytotoxicity to Hela cells than free DOX and DOXloaded MP-PNAAE microgels. The results suggest that MTHF may represent a potential ligand for targeted anticancer drug delivery, and the MP-PNAAEF and MP-PNAAEM magnetic microgels may represent a potential tumor targeting drug carrier.
\end{abstract}

\section{Main text}

\subsection{Introduction}

A successful nanocarrier for drugs may be engineered to present high biocompatibility, colloidal stability, protection of active therapeutic drugs, improved pharmacokinetics, and evade the reticuloendothelial system. Furthermore, surface-modification of the nanocarriers can control the release of the drug in response to different external stimuli such as $\mathrm{pH}^{\mathbf{1}}{ }^{1}$ temperature, ${ }^{2}$ light ${ }^{3}$ magnetic field, ${ }^{4}$ redox reactions, ${ }^{5}$ enzymes $^{6}$ and even antibodies, ${ }^{7}$ and thus greatly improve pharmacokinetics. Recently, dual stimuli-responsive or ternary stimuli-responsive nanocarriers have been prepared and applied in extended fields, especially in controlled-release drug delivery systems (DDS). ${ }^{\mathbf{8}, \mathbf{9}}$

It has been accepted that targeted delivery is very necessary for anticancer drug delivery systems, since most of the

${ }^{a}$ School of Chemistry and Molecular Engineering, East China University of Science and Technology, Shanghai, 200237, China. E-mail: wfh@ecust.edu.cn; Fax: +86-2164252973; Tel: +86-21-64252973

${ }^{b}$ School of Chemical and Environmental Engineering, Shanghai Institute of Technology, Shanghai, 201418, China commonly used anticancer drugs have serious side effects due to unspecific action on healthy cells; moreover, targeted delivery would enhance the therapeutic efficacy. To date, many efforts have been made to design the drug delivery vehicles based on microgels for targeted anticancer drug delivery. ${ }^{10,11}$ One strategy is to prepare magnetic microgels as delivery vehicles for targeting anticancer drugs to cancer organs or tissues by using a magnetic field. Zhang et al. synthesized $\mathrm{Fe}_{3} \mathrm{O}_{4} / \mathrm{P}(\mathrm{AA}-\mathrm{MAA}-$ NIPAm) magnetic composite microspheres by controlled radical polymerization in the presence of DPE. ${ }^{12}$ Kang et al. demonstrated the preparation of PAA-modified $\mathrm{Fe}_{3} \mathrm{O}_{4}$ microspheres; the PAA polymer was encapsulated in the inner cavity of $\mathrm{Fe}_{3} \mathrm{O}_{4}$ hollow spheres by a vacuum casting route and photo-initiated polymerization. ${ }^{\mathbf{1 3}}$ Shamim et al. synthesized polymer coated nanomagnetic adsorbents by seed polymerization using surface modified nanomagnetic particles as the seeds. These magnetic microgels have the potential to be used as targeted delivery vehicles. $^{8}$

Another well-known and widely accepted strategy is cellular targeting by utilizing antibodies or specific ligands to selectively bind to the cell surface to trigger receptor-mediated endocytosis, which could enhance the efficiency of cell uptake of drug 
delivery systems, and significantly improve the therapeutic efficacy. Folic acid (FA) is a non-immunogenic receptor-specific ligand that has relatively simple and well-defined conjugation chemistry. It has emerged as an attractive specific ligand for targeted anticancer drug delivery ${ }^{\mathbf{1 4}}$ because folate receptors are often overexpressed on the surface of human cancer cells. ${ }^{15} \mathrm{~A}$ wide range of folate-nanoparticle conjugates, including those of superparamagnetic nanoparticles, ${ }^{16,17}$ gold nanoparticles ${ }^{\mathbf{1 8}}$ and mesoporous silica nanoparticles, ${ }^{19}$ have already been investigated. FA ligands are readily linked to the amino group of PEI by amide reaction. Rosenholm et al. grafted folate on PEI modified mesoporous silica nanoparticles. ${ }^{20}$ The results indicated that FA modified PEI-silica particles were able to specifically target folate receptor expressing cancer cells, and 5-times more particles were internalized by cancer cells expressing low levels of the receptor. Wang et al. developed an impedance cytosensor for the high-sensitivity detection of Hela cells based on the folate conjugated-PEI-CNT. ${ }^{21}$ Therefore, folateconjugated PEI particles facilitate the efficiency of cell uptake by cancer cells due to receptor-mediated endocytosis.

Methotrexate (MTX), an analogue of folic acid, exhibits not only a targeting role as folic acid, but also has a therapeutic effect on many types of cancer cells that overexpress folate receptors on their surfaces. ${ }^{22}$ As such, several molecular conjugates of MTX have been synthesized in order to redirect the drug to specific target tissues, enhance cell uptake, or tune the toxicity and therapeutic profile. ${ }^{23,24}$ L-5-Methyltetrahydrofolate (MTHF), another analogue of folic acid, has short chains and a small size, and is stable, non-immunogenic and has well-defined conjugation chemistry. Using radiolabeled folic acid, the great specificity and affinity for folates and folate analogues has been detailed. ${ }^{25}$ The affinity for folate receptors (FR $\alpha)$ by MTHF is similar to that of folic acid and normal brain development and function depend on the active transport of folates across the blood-brain barrier. The FR $\alpha$ protein is localized at the basolateral surface of the choroid plexus, which is characterized by a high binding affinity for circulating MTHF. ${ }^{26}$ Therefore MTHF may emerge as an attractive specific ligand for targeted blood-brain drug delivery; however, less progress has been made in this department.

Recently, the applications of multi-responsive microgels in the biomedical and biotechnological fields have drawn increasing interest. The hydrogel containing poly $\mathrm{N}$-isopropyl acrylamide (PNIPAM) and branched polyethyleneimine (PEI) ${ }^{27}$ and the copolymer PNIPAM-co-PEI ${ }^{28,29}$ show the same thermosensitive capacity as PNIPAM hydrogels, and show a higher transfection efficiency. ${ }^{\mathbf{3 0}}$

It can be imagined that folate- and MTHF-conjugated PNIPAM-co-PEI magnetic microgels, combining thermo- and $\mathrm{pH}-$ sensitivity, high transfection efficiency, receptor-mediated targeting, and magnetic targeting, would significantly improve delivery efficiency and therapeutic efficacy. However, to the best of our knowledge, no report on the design of folate- or MTHFconjugated magnetic microgels for targeted anticancer drug delivery has been found. In the present study, the magnetic $\mathrm{Fe}_{3} \mathrm{O}_{4}$ nanoparticles covered with novel thermo- and $\mathrm{pH}-$ responsive microgels have been prepared by the graft copolymerization of PEI $\left(M_{\mathrm{n}}=1800\right)$ onto NIPAM. In addition, as attractive targeting ligands, folate or MTHF has been conjugated with the magnetic microgels for selective delivery. In vitro release experiments revealed that sustained release of DOX at $\mathrm{pH} 4.5$ would be more effective, and the effects of DOX-loaded MP-PNAAE, DOX-loaded MP-PNAAEF and DOX-loaded MPPNAAEM microgels on cytotoxicity against Hela cells were also investigated. The results suggest that the resultant microgels may represent a potential application as tumor targeting drug carrier.

\subsection{Experimental}

Materials. $N$-Isopropylacrylamide (NIPAM) and $N, N^{\prime}$-methylene bisacrylamide (MBA) were purchased from Tokyo Chemical Industry Co. Ltd. (Japan). Branched polyethyleneimine (PEI, MW: 1800) was purchased from Shanghai Meryer Chemical Reagents Company (China). Doxorubicin hydrochloride salt (DOX) was purchased from Taizhou Shenxin United Co. Ltd. (China). Acrylic acid (AA), folic acid (FA), L-5-methyltetrahydrofolate (MTHF), ammonium persulfate (APS), sodium dodecyl sulfate (SDS), dicyclohexylcarbodiimide (DCC), $N$-hydroxysuccinimide (NHS), ferric chloride $\left(\mathrm{FeCl}_{3} \cdot 6 \mathrm{H}_{2} \mathrm{O}\right)$, ferrous sulfate $\left(\mathrm{FeSO}_{4} \cdot 7 \mathrm{H}_{2} \mathrm{O}\right)$ and ammonium citrate tribasic (citric) were obtained from Shanghai Chemical Reagents Company (Shanghai, China). NIPAM was recrystallized from hexane solution and dried in a vacuum prior to use. Human cervical carcinoma cell line, Hela and human liver cell line, L02 were purchased from China Center for Typical Culture Collection (China). The growth medium (RPMI-1640) was purchased from Invitrogen (USA), fetal calf serum (FCS) and trypsin were purchased from Hyclone (USA), Hoechst 33342 was purchased from Jiang Lai Biotechnology Co. Ltd. (China). 3-(4,5Dimethylthiazol-2-yl)-2,5-diphenyl tetrazolium bromide (MTT) was purchased from Sigma-Aldrich Co. (USA). All other reagents and solvents used in the study were analytical grade and obtained from commercial sources.

Preparation of magnetite nanoparticles. Magnetite nanoparticles $\left(\mathrm{Fe}_{3} \mathrm{O}_{4}\right.$ magnetic fluid) were prepared by the previously reported co-precipitation method ${ }^{31}$ with minor modifications. Briefly, $8.3 \mathrm{~g} \mathrm{FeSO}_{4} \cdot 7 \mathrm{H}_{2} \mathrm{O}$ and $16.2 \mathrm{~g} \mathrm{FeCl}_{3} \cdot 6 \mathrm{H}_{2} \mathrm{O}$ were dissolved in $700 \mathrm{~mL}$ of distilled $\mathrm{H}_{2} \mathrm{O}$ with mechanical stirring in nitrogen atmosphere for $0.5 \mathrm{~h}$. Then, $60 \mathrm{~mL} \mathrm{NH}_{3} \cdot \mathrm{H}_{2} \mathrm{O}$ were dropped into the above $\mathrm{Fe}^{3+} / \mathrm{Fe}^{2+}$ solution. After stirring for $1 \mathrm{~h}$, the temperature was heated to $90^{\circ} \mathrm{C}$ and maintained for $2 \mathrm{~h}$. The resulting magnetite nanoparticles were collected with a magnet and washed with $2 \mathrm{M} \mathrm{HNO}_{3}$, then washed several times with deionized water until neutral. The obtained magnetite nanoparticles were redispersed in $200 \mathrm{~mL}$ of ammonium citrate tribasic solution $(0.5 \mathrm{M})$, and stirred for $1 \mathrm{~h}$ at $90{ }^{\circ} \mathrm{C}$, then collected with a magnet and washed three times with deionized water and acetone, respectively. The magnetite nanoparticles (abbreviated as MP) were then dried under vacuum, and stored under vacuum until use.

Preparation of MP-PNAAEF microgels. The thermosensitive polymer of carboxyl-ended poly(NIPAM) coated magnetite nanoparticle microgels (MP-PNAA) was synthesized by free- 
radical copolymerization of NIPAM and AA in water using APS and MBA as an initiator and a cross-linking agent, according to a previous report ${ }^{32}$ with a few modifications.

In the next step, the carboxyl-ended MP-PNAA was copolymerized with the amine groups of PEI by the reaction of the carboxylic acid groups activated with dicyclohexylcarbodiimide. In a typical reaction, the above resultant MP-PNAA (300 mg), DCC (124 mg) and NHS $(69 \mathrm{mg})$ were dissolved in $20 \mathrm{~mL}$ DMSO containing $200 \mu \mathrm{L}$ triethylamine and the mixture was stirred for $5 \mathrm{~h}$ at room temperature. The solution was added to a large excess of PEI $(450 \mathrm{mg})$ in $10 \mathrm{~mL}$ DMSO with vigorous stirring. After $24 \mathrm{~h}$, the magnetic microgels with PEI grafted to MP-PNAA (designated as MP-PNAAE), were precipitated in water. The precipitated sample was isolated by centrifugation, and then purified by dialysis against distilled water (MWCO 8000-14000) to remove the unreacted $1800 \mathrm{Da}$ PEI and other residues. The products were then dried under vacuum, and stored under vacuum until use.

Finally, FA (100 mg) was activated with DCC $(31 \mathrm{mg})$ and NHS (26 mg), and dissolved in DMF/DMSO (9 mL $3: 1$ ) solution with stirring for $4 \mathrm{~h}$. Subsequently, the MP-PNAAE microgels (300 $\mathrm{mg}$ suspended in $20 \mathrm{~mL}$ DMSO) were added to the activated FA solution and allowed to react with stirring under anhydrous conditions overnight at room temperature. After the reaction, the mixture was centrifuged and washed with DMSO, water and ethanol several times to obtain FA modified polymer magnetic microgels (designated as MP-PNAAEF).

Similarly, MTHF $(100 \mathrm{mg})$ was activated by DCC $(31 \mathrm{mg})$ and NHS $(26 \mathrm{mg}$ ), dissolved in DMF/DMSO (9 mL $3: 1$ ) solution with stirring for $4 \mathrm{~h}$, and then, MP-PNAAEM microgels were successfully prepared by the same method.

Characterization of MP-PNAAEF magnetic microgels. Fourier transform infrared spectra (FT-IR) were obtained on a Thermo Nicolet 6700 FT-IR spectrometer with the KBr method. The morphology of magnetite nanoparticles, MPPNAAEF and PNAAEF microgels were observed using transmission electron microscopy (TEM, JEM-1400). The samples were placed onto carbon coated copper grids, stained with phosphotungstic acid and dried at room temperature. The microgel size, zeta potential and distribution of MP-PNAA, MPPNAAE and MP-PNAAEF microgels at different temperatures and $\mathrm{pH}$ were measured using a Zetasizer Nano-ZS90 analyzer based on the dynamic light scattering (DLS) technique. Before measurement, the microgels were appropriately diluted with distilled water. Thermogravimetric analysis (TGA) was performed with a TA instrument SDT Q600 from $25{ }^{\circ} \mathrm{C}$ to $700{ }^{\circ} \mathrm{C}$ under $\mathrm{N}_{2}$ at a heating rate of $20^{\circ} \mathrm{C} \mathrm{min}{ }^{-1}$. Powder XRD patterns of the microgels were collected on a Spectris X-pert PRO. Fluorescence microscopy images were observed by fluorescence microscope (DMIRB).

Loading of doxorubicin (DOX). The drug loading and release behavior of the resultant MP-PNAAE microgels at different temperatures and $\mathrm{pH}$ environments were investigated with DOX as a model molecule. The DOX-loaded MP-PNAAEF microgels were prepared as follows: $20 \mathrm{mg}$ MP-PNAAEF microgel were mixed with $2 \mathrm{~mL}$ DOX solution in deionized water $\left(2 \mathrm{mg} \mathrm{mL}^{-1}\right)$. The mixture was stirred in an orbital shaker at $220 \mathrm{rpm}$ and
$25{ }^{\circ} \mathrm{C}$ for $72 \mathrm{~h}$. The DOX-loaded magnetic microgels were separated by centrifuging at $14000 \mathrm{rpm}$ for $20 \mathrm{~min}$, and then washed with $23 \mathrm{~mL}$ deionized water. The resulting DOX-loaded MP-PNAAEF magnetic microgels were frozen and lyophilized to obtain the dried product. To evaluate the amount of DOX loaded, the residual DOX content $\left(R_{\mathrm{DOX}}\right)$ was measured using a UV spectrophotometer at a wavelength of $480 \mathrm{~nm}$. The DOXloading content and encapsulation efficiency of the magnetic microgels were calculated using the following equations:

$$
\begin{aligned}
\text { DOX loading content }(\mathrm{LC} \%)= & \left(\left(O_{\mathrm{DOX}}-R_{\mathrm{DOX}}\right) / M_{\mathrm{NPs}}\right) \\
& \times 100 \%
\end{aligned}
$$

DOX encapsulation efficiency $(\mathrm{LE} \%)=\left(\left(O_{\mathrm{DOX}}-R_{\mathrm{DOX}}\right) / O_{\mathrm{DOX}}\right)$

$$
\times 100 \%
$$

here, $O_{\mathrm{DOX}}$ is the original DOX content, $M_{\mathrm{NPs}}$ is the amount of lyophilized magnetic microgels.

In vitro release of DOX. A $10 \mathrm{mg}$ sample of the above prepared DOX-loaded MP-PNAAEF microgels was immersed in $5 \mathrm{~mL}$ of PBS at $37^{\circ} \mathrm{C}$ and shaken at $200 \mathrm{rpm}$. At certain time intervals, $3 \mathrm{~mL}$ of solution were taken out and centrifuged to determine the concentration of DOX released, and $3 \mathrm{~mL}$ of fresh PBS was added to the tube containing the DOX-loaded MPPNAAEF microgels. The concentration of DOX in the above collected solution was determined using a UV spectrophotometer at $480 \mathrm{~nm}$. In order to investigate the influence factor of DOX release, different conditions were applied, such as $\mathrm{pH} 7.4$ and $37{ }^{\circ} \mathrm{C}$; $\mathrm{pH} 4.5$, and $37{ }^{\circ} \mathrm{C}$; $\mathrm{pH} 7.4$ and $45{ }^{\circ} \mathrm{C}$; $\mathrm{pH} 4.5$ and $45{ }^{\circ} \mathrm{C}$.

Cell culture. Hela and L02 cell lines were maintained in 1640 medium, containing $10 \%$ fetal bovine serum, 100 units per $\mathrm{mL}$ penicillin, and $100 \mathrm{mg} \mathrm{mL}^{-1}$ streptomycin. Cells were cultured with the complete medium in $5 \% \mathrm{CO}_{2}$ at $37^{\circ} \mathrm{C}$. For all experiments, cells were harvested from subconfluent cultures by the use of trypsin and were re-suspended in fresh complete medium before plating.

Cell viability assay. In vitro cytotoxicities of MP-PNAAE, MPPNAAEF and MP-PNAAEM microgels were assessed using 3-[4,5dimethylthiazol-2-yl]-2,5-diphenyltetrazolium bromide (MTT) assay. The cells were seeded into a 96-well plate at 10000 cells per well for $24 \mathrm{~h}$ to allow the cells to attach and then were exposed to the serial concentrations of MP-PNAAE, MP-PNAAEF and MPPNAAEM microgels in $5 \% \mathrm{CO}_{2}$ at $37^{\circ} \mathrm{C}$. After $48 \mathrm{~h}$ incubation, the medium containing microgels was removed, and freshly prepared culture media $(100 \mu \mathrm{L})$ and $10 \mu \mathrm{L}$ of MTT solution (diluted in a culture medium with a final concentration of $5 \mathrm{mg} \mathrm{mL}^{-1}$ ) was added and incubated for an additional $4 \mathrm{~h}$. The medium was then replaced with $100 \mu \mathrm{L}$ of dimethyl sulfoxide (DMSO) to dissolve the internalized purple formazan crystals, and the absorbance was monitored using a microplate reader at wavelengths of $492 \mathrm{~nm}$ and $630 \mathrm{~nm}$. The absorbance readings of the formazan crystals were taken by the substraction of absorbances at $492 \mathrm{~nm}$ from those at $630 \mathrm{~nm}$. Cytotoxicity was expressed as the percentage cell viability, compared to the untreated control cells.

In vitro cytotoxicity testing. The cells were seeded in a 96-well plate at a density of 10000 cells per well and cultured in $5 \% \mathrm{CO}_{2}$ 
at $37{ }^{\circ} \mathrm{C}$ for $24 \mathrm{~h}$. Then, free DOX, DOX-loaded MP-PNAAE, MPPNAAEF, and MP-PNAAEM microgels were added to the medium; the concentrations of DOX were $0.25,0.5,1,2$, and 1 $\mu \mathrm{g} \mathrm{mL}{ }^{-1}$, respectively, and the cells were incubated in $5 \% \mathrm{CO}_{2}$ at $37{ }^{\circ} \mathrm{C}$ for $24 \mathrm{~h}$, and then washed carefully with PBS to remove DOX, DOX-loaded MP-PNAAE, DOX-loaded MP-PNAAEF, DOXloaded MP-PNAAEM microgels.

$$
\text { Cell viability }(\%)=[A]_{\text {test }} /[A]_{\text {control }} \times 100
$$

Cell uptake. To investigation the cell uptake of MP-PNAAE, MP-PNAAEF and MP-PNAAEM microgels, the microgels were loaded with DOX to form DOX-loaded MP-PNAAE, MP-PNAAEF and MP-PNAAEM microgels. In a typical procedure, the Hela or L02 cells were seeded in 24-well culture plates (a clean cover slip was put in each well) and grown overnight to allow the cells to attach. After the cells were washed twice with PBS, DOX-loaded MP-PNAAE, DOX-loaded MP-PNAAEF and DOX-loaded MPPNAAEM microgel solutions with a DOX concentration of $2 \mu \mathrm{g}$ $\mathrm{mL}^{-1}$ for each solution were added to the culture plates and were incubated at $37^{\circ} \mathrm{C}$ for $15 \mathrm{~min}, 30 \mathrm{~min}, 1 \mathrm{~h}$ and $2 \mathrm{~h}$, then the cells were washed with PBS three times to remove the remaining microgel and dead cells. Subsequently, to perform nucleus labeling, the nuclei were stained with Hoechst 33342 solution (5 $\mu \mathrm{g} \mathrm{mL} \mathrm{m}^{-1}$ in the culture solution, $500 \mu \mathrm{L}$ per well) for $20 \mathrm{~min}$ and then washed three times with PBS. The cover slips were placed on a glass microscope slide, and the samples were visualized using fluorescence microscopy.

\subsection{Results and discussion}

Folate- or methyltetrahydrofolate-conjugated magnetic microgels were successfully developed. As shown in Scheme 1, the $\mathrm{Fe}_{3} \mathrm{O}_{4}$ nanomagnetic particles were prepared by chemical precipitation of $\mathrm{Fe}^{2+}$ and $\mathrm{Fe}^{3+}$ salts in the ratio of $1: 2$ under alkaline and inert conditions, the surfaces of these particles were modified with trisodium citrate to achieve stability against agglomeration (MP). Thermo- and pH-sensitive polymer (poly(NIPAM-co-AA)) coated nanomagnetic particles were synthesized by seed polymerization using MP particles as the seeds. After conjugating the PEI chains via amide reaction, FA or MTHF ligands were successfully grafted onto MP-PNAAE via amide reaction, and MP-PNAAEF and MP-PNAAEM were obtained, respectively.

Characterization of prepared microgels. The FTIR spectra of MP-PNAA, MP-PNAAE, MP-PNAAEF and MP-PNAAEM microgels are shown in Fig. 1A. Notably, the bending frequencies of the amide $\mathrm{N}-\mathrm{H}$ at $1636 \mathrm{~cm}^{-1}$ and $1550 \mathrm{~cm}^{-1}$ indicate the presence of the amide carbonyl group in MP-PNAA. The $1387 \mathrm{~cm}^{-1}$ peak is the characteristic absorption of the isopropyl group. The absorbance at $1715 \mathrm{~cm}^{-1}$ is assigned to the stretching vibration of the $-\mathrm{C}=\mathrm{O}$ bond of acrylic acid, which is weaker than the amide carbonyl group, demonstrating the presence of hydrogen bonds. Due to the overlapping of the amide $\mathrm{N}-\mathrm{H}$ peaks of both PEI and poly(NIPAM), the FTIR spectrum of MP-PNAAE is similar to that of MP-PNAA. However, it is found that the absorbance of amide $\mathrm{N}-\mathrm{H}$ in MP-PNAAE (Fig. 1b) is greatly enhanced as compared to that of MP-PNAA, indicating that the PEI is successfully grafted onto MP-PNAA. The absorption peak at $1604 \mathrm{~cm}^{-1}$ is assigned to the vibration of the benzene ring of FA or MTHF as indicated by the arrows in Fig. 1c and d, revealing that FA or MTHF exists in the copolymer chains. This peak is not prominently attributed to the overlap of the amide carbonyl group in the sample. It is important to note that the characteristic absorption peaks of $\mathrm{Fe}_{3} \mathrm{O}_{4}$ magnetic nanoparticles at $610 \mathrm{~cm}^{-1}$ were clearly observed in all spectra. ${ }^{8}$ The characteristic peaks of the $\mathrm{Fe}-\mathrm{O}$ bond of bulk $\mathrm{Fe}_{3} \mathrm{O}_{4}$ were observed at 570 and $375 \mathrm{~cm}^{-1}$. When the $\mathrm{Fe}_{3} \mathrm{O}_{4}$ particles were reduced to nanoscale size, the effect of the finite size of the nanoparticles led to the increase of the surface bond force
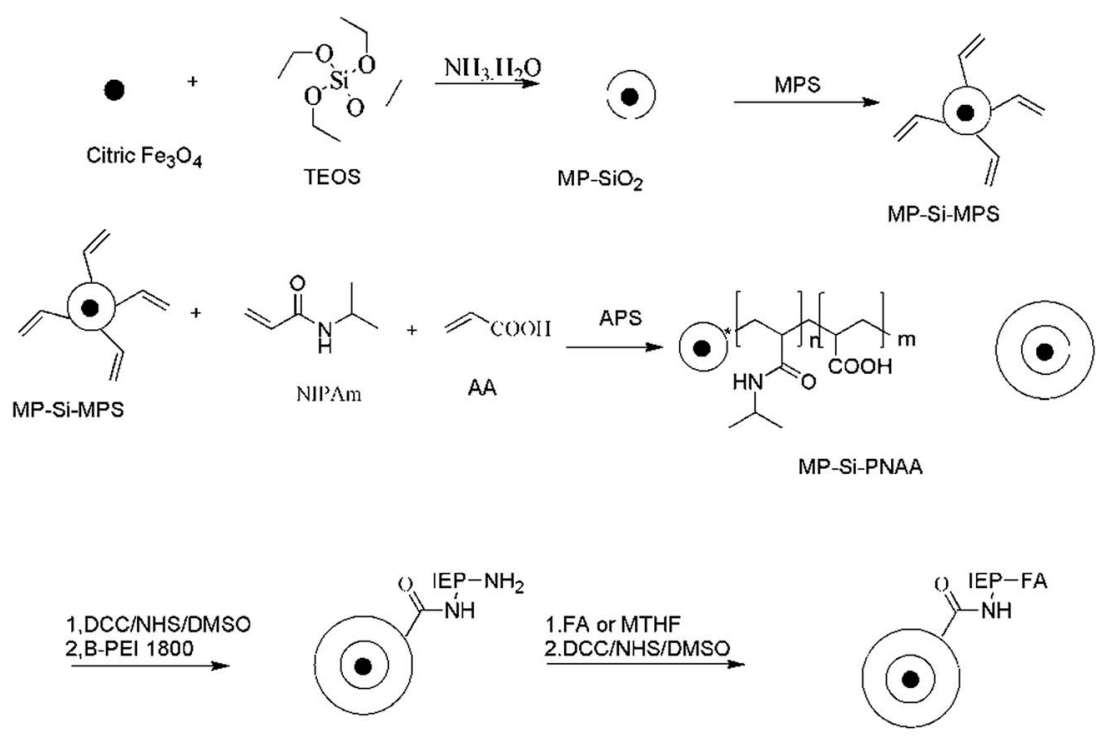

MP-Si-PNAAE

MP-Si-PNAAEF(MP-Si-PNAAEM)

Scheme 1 Preparation procedure of MP-PNAAEF or MP-PNAAEM. 


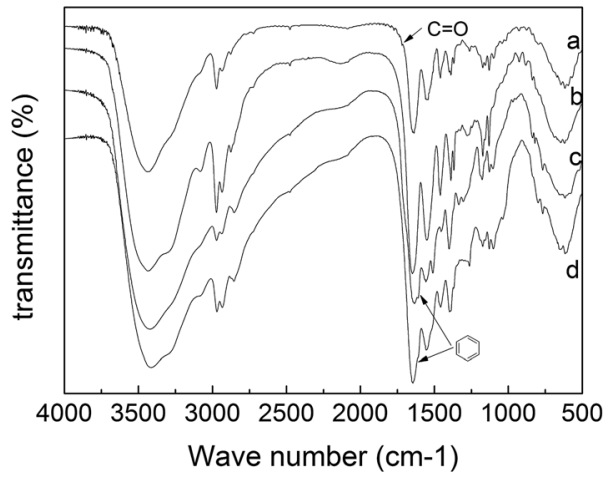

Fig. 1 FTIR spectra of (a) MP-PNAA; (b) MP-PNAAE; (c) MP-PNAAEF; (d) MP-PNAAEM

constant. Numerous surface atom bonds were broken, resulting in the rearrangement of nonlocalized electrons on the nanoparticle surface; therefore, the characteristic peak of the $\mathrm{Fe}-\mathrm{O}$ bond was blue-shifted to higher wavenumber.

Zeta potential measurements were used to characterize the surface charges of the as-prepared particles. The mean zeta potential value of MP-PNAA microgels without modification was $-17.15 \pm 0.32 \mathrm{mV}$ at $37^{\circ} \mathrm{C}$. This is attributed to the rich carboxyl groups on the surface of the microgels. However, for MPPNAAE, MP-PNAAEF and MP-PNAAEM microgels, the values were $38.23 \pm 1.23 \mathrm{mV}, 25.87 \pm 0.65 \mathrm{mV}$ and $28.29 \pm 0.44 \mathrm{mV}$ at $37{ }^{\circ} \mathrm{C}$, respectively. The charge of the modified microgels changed to positive, indicating the successful modification of PEI on the outer surface of MP-PNAA. Compared to the zeta potential of MP-PNAAE, the decreased values of MP-PNAAEF and MP-PNAAEM demonstrated that FA and MTHF were covalently linked to the amino group of PEI by the amide reaction.

Morphologies of microgels. The X-ray powder diffraction patterns of the bare and polymer coated magnetic nanoparticles were measured. It is to be noted that MP is the dominant phase in all samples, but obviously, the entire peak is broadened. Compared with PNAAEF, five characteristic peaks for MP, i.e., peaks (220), (311), (400), (511) and (440), were observed for other samples (including MP-PNAA, MP-PNAAE, MP-PNAAEF and MPPNAAEM), suggesting that the resultant particles are pure MP with a spinel structure. The intensities of the diffraction peaks are much weaker compared to MP, which is probably caused by the polymer coating. This implies that the binding process did not lead to any change in crystal structures for MP embedded in polymer. The crystallization of MP nanoparticles at the most intense peak, corresponding to the (311) reflection in MP is related to the mean size of the nanocrystals, according to the Debye-Scherrer's formula, ${ }^{33} D=0.89 \lambda / B \cos \theta$, where $D$ is the crystallite size, $\lambda$ is the wavelength of X-rays used, $\theta$ is the diffraction angle, and $B$ is the full-width at half maximum. The average crystallite size was determined to be $9.9 \mathrm{~nm}$.

Fig. 2b shows TEM images of PNAAEF microgels. As expected, those microgels are monodisperse, and their average particle size is about $180 \mathrm{~nm}$, smaller than that measured by DLS, which is due to the PNAAEF swelling in the water. From the microimages of MP-PNAAEF, as shown in Fig. 2a, it is clear

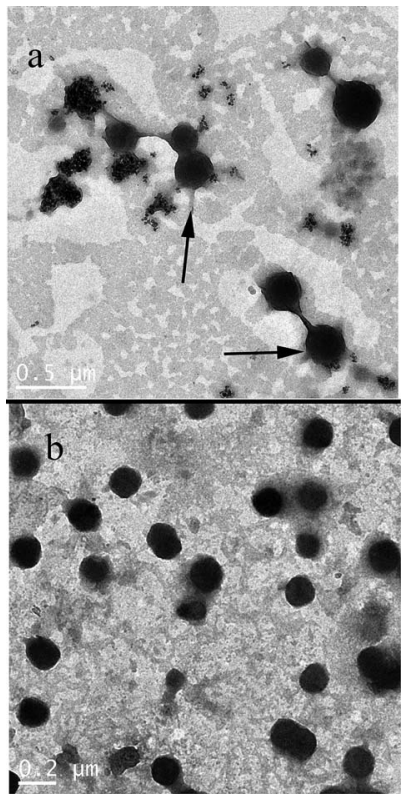

Fig. 2 TEM microimages of microgels (a) MP-PNAAEF; (b) PNAAEF.

that the aggregated MP particles with PNAAEF coating are irregular in shape, and the non-aggregated MP particles with PNAAEF coating are fairly spherical (Fig. 2a, indicated by the arrows). Also, the mean diameter of black MP particles is about $10 \mathrm{~nm}$. This is consistent with the XRD results obtained using Debye-Scherrer's formula.

Generally, magnetic particles bond with polymer via van der Waals forces, hydrogen bonds, chelation of the metal ion on the surface of magnetic particles to the polymer $\operatorname{chain}^{13}$ and formation of covalent bonds through the modified surfaces of magnetic particles. ${ }^{8,12}$ The average particle size of MP-PNAAEF is marginally larger than PNAAEF. With the incorporation of MP into the reaction solution, due to the change of the reaction from a homogeneous system, the MPs became the precipitation centers for polymerization to form magnetic microgels embedded in the polymer. Furthermore, the TGA results for MPPNAAEF show about $73.72 \%$ mass loss. This indicates that the magnetic microgels contain $26.28 \%$ of inorganic magnetite.

Magnetite nanoparticles $\left(\mathrm{Fe}_{3} \mathrm{O}_{4}\right.$ magnetic fluid) were prepared by the co-precipitation method according to a previous report, ${ }^{34}$ with minor modifications. Deng et al. demonstrated a new approach for the convenient preparation of thermoresponsive polymer magnetic microspheres with a welldefined core-shell structure, and just used about $2 \%$ magnetite nanoparticles. However, based on our precious work, ${ }^{35}$ to ensure higher magnetic properties, we increased the magnetite nanoparticles to $5 \%$.

The thermosensitivity of magnetic microgels. Fig. 3 shows the effect of temperature on the sizes of various samples. It was found that with the increase in incorporation temperature, the size of all magnetic microgels changed dramatically in neutral environment. For MP-PNAAEF microgels, as the temperature went below the volume phase transition temperature (VPTT) of the microgels in the swollen state, the size of the microgels was 
$300 \mathrm{~nm}$. With increasing temperature, due to the collapse of the PNAAEF network, the MP-PNAAEF microgels were in the deswelling state, resulting in a smaller size $(235 \mathrm{~nm})$. This indicates that the introduction of FA into the copolymer remarkably alters the volume phase transition properties of magnetic microgels.

According to Fig. 3, the VPTT of MP-PNAA, MP-PNAAE, MPPNAAEF and MP-PNAAEM microgels were $33{ }^{\circ} \mathrm{C}, 43{ }^{\circ} \mathrm{C}, 38{ }^{\circ} \mathrm{C}$ and $40{ }^{\circ} \mathrm{C}$, respectively. Compared to MP-PNAA microgels, the MP-PNAAE microgels show a higher VPTT. This may be ascribed to the incorporated PEI, which could make the microgels more hydrophilic. The hydrogen bonds between the amino groups of PEI and water molecules can result in a higher VPTT, while the VPTT of MP-PNAAEF and MP-PNAAEM are lower than MPPNAAE. This is probably caused by the disappearance of some amino groups after the reaction between carboxyl groups of FA or MTHF, and the inclusion of a hydrophobic group of pteridine for FA or MTHF, which makes the microgels more hydrophobic than MP-PNAAE.

The $\mathbf{p H}$ sensitivity of MP-PNAAEF microgels. The results for the effect of $\mathrm{pH}$ values on the particle size of MP-PNAAEF are shown in Fig. 4. At $37{ }^{\circ} \mathrm{C}$, the particle size of MP-PNAAEF decreases from 191.1 to $153.6 \mathrm{~nm}$ with an increase in $\mathrm{pH}$ from 3.0 to 5.2 , and increases to $186.9 \mathrm{~nm}$ with a further increase in $\mathrm{pH}$ to 11.1. MP-PNAAEF contains amino groups of PEI and carboxylic groups of unreacted AA and FA. At low $\mathrm{pH}$ the amino groups become protonated, which can lead to the disruption of the complex. As a result, poly(NIPAM) becomes a neutral molecule and there are some electrophorus PEI chains in the microgel. The electrostatic repulsive forces of inter-PEI molecules result in the large size of the particles. Likewise, at high pH the carboxylic groups become ionized, leading to broken hydrogen bonds and swollen microgels, which increase the particle size of microgels formed. At pH 5, most carboxylic groups are protonated; besides the great majority amino groups being un-ionized, there are existing hydrogen bonds between carboxylic groups or amino groups

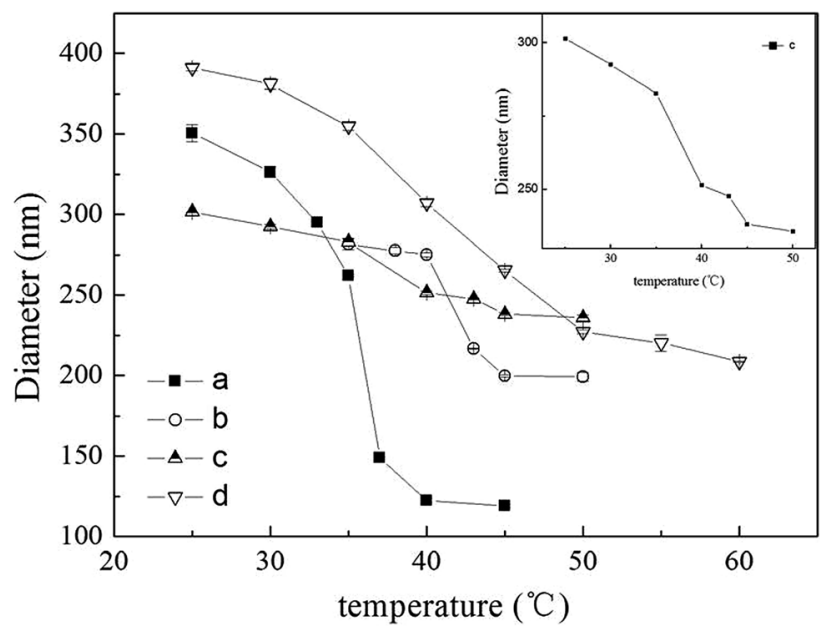

Fig. 3 The effect of temperature on diameter of microgels MP-PNAA (b) MP-PNAAE; (c) MP-PNAAEF; (d) MP-PNAAEM.

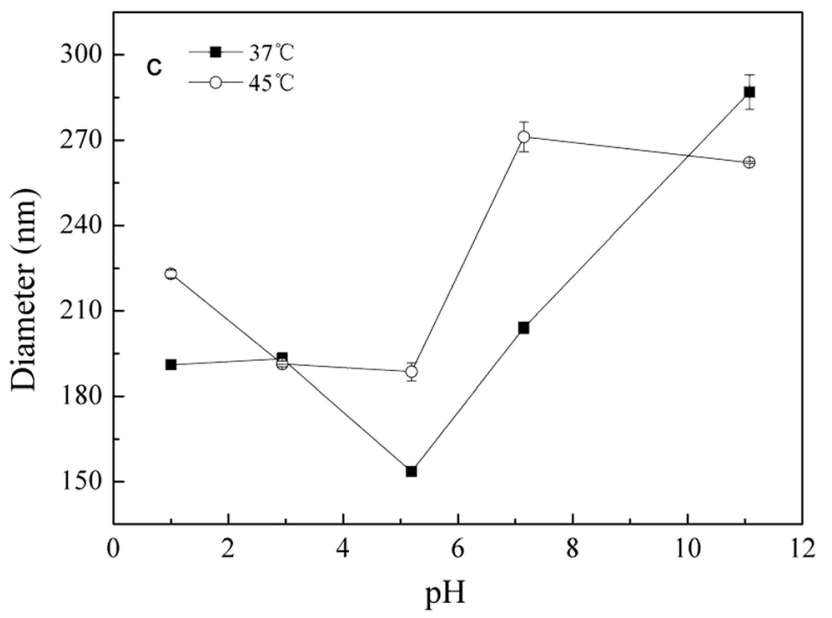

Fig. 4 The effect of $\mathrm{pH}$ on the diameter of MP-PNAAEF microgels at $37^{\circ} \mathrm{C}$ and $45^{\circ} \mathrm{C}$.

and acylamino of poly(NIPAM) or water molecules, which could cause the network of microgels to become constricted. The results discussed above indicate that MP-PNAAEF microgels are $\mathrm{pH}$ sensitive. Thus, by the adjustment of medium $\mathrm{pH}$, the size of the polymer magnetic microgels could be well controlled.

Loading and release behavior of DOX on microgels. For the purpose of determining the drug delivery by MP-PNAAEF and MP-PNAAEF microgels as delivery vehicles, doxorubicin hydrochloride (DOX), an anticancer drug, was used as the model drug to be loaded into MP-PNAAE, MP-PNAAEF and MP-PNAAEM microgels. The loading efficiencies of DOX in MP-PNAAE, MPPNAAEF and MP-PNAAEM microgels were $47.6 \%, 65.4 \%$ and $54.2 \%$, respectively. The DOX loading amounts in MP-PNAAE, MP-PNAAEF and MP-PNAAEM microgels were 78, 130 and $134 \mathrm{mg} \mathrm{g}^{-1}$, respectively. This indicates that compared with MPPNAAE, FA or MTHF the modified MP-PNAAE microgels equally improved the amount of DOX loaded.

The release profiles of DOX from the DOX-loaded MP-PNAAE and MP-PNAAEF microgels in NaAc-HAc ( $\mathrm{pH} 4.5)$ at $45{ }^{\circ} \mathrm{C}$ are shown in Fig. 5A. The three microgels exhibited typical sustained release behaviors. A fast release happened within $10 \mathrm{~h}$, followed by a relatively slow release rate until the end of assay testing. However, it was found that the release rate of both MPPNAAEF and MP-PNAAEM microgels is slower than that of MPPNAAE microgels. The volume phase transition properties of magnetic microgels may be appreciably impacted by the incorporated FA or MTHF. As illustrated in Fig. 4, with increased temperature, the size of MP-PNAAE and MP-PNAAEF microgels shrank from 316 to $200 \mathrm{~nm}$ and 301 to $235 \mathrm{~nm}$, respectively. In other words, the de-swelling degree of MPPNAAE microgels is larger compared to MP-PNAAEF, thus leading to a faster release rate and a greater cumulative release amount. By contrast, the release rate of MP-PNAAEM microgels is slower than that of MP-PNAAEF microgels. This is attributed to the characteristic difference between FA and MTHF. As seen from Fig. 5A, the MP-PNAAEF microgels are completely in the 

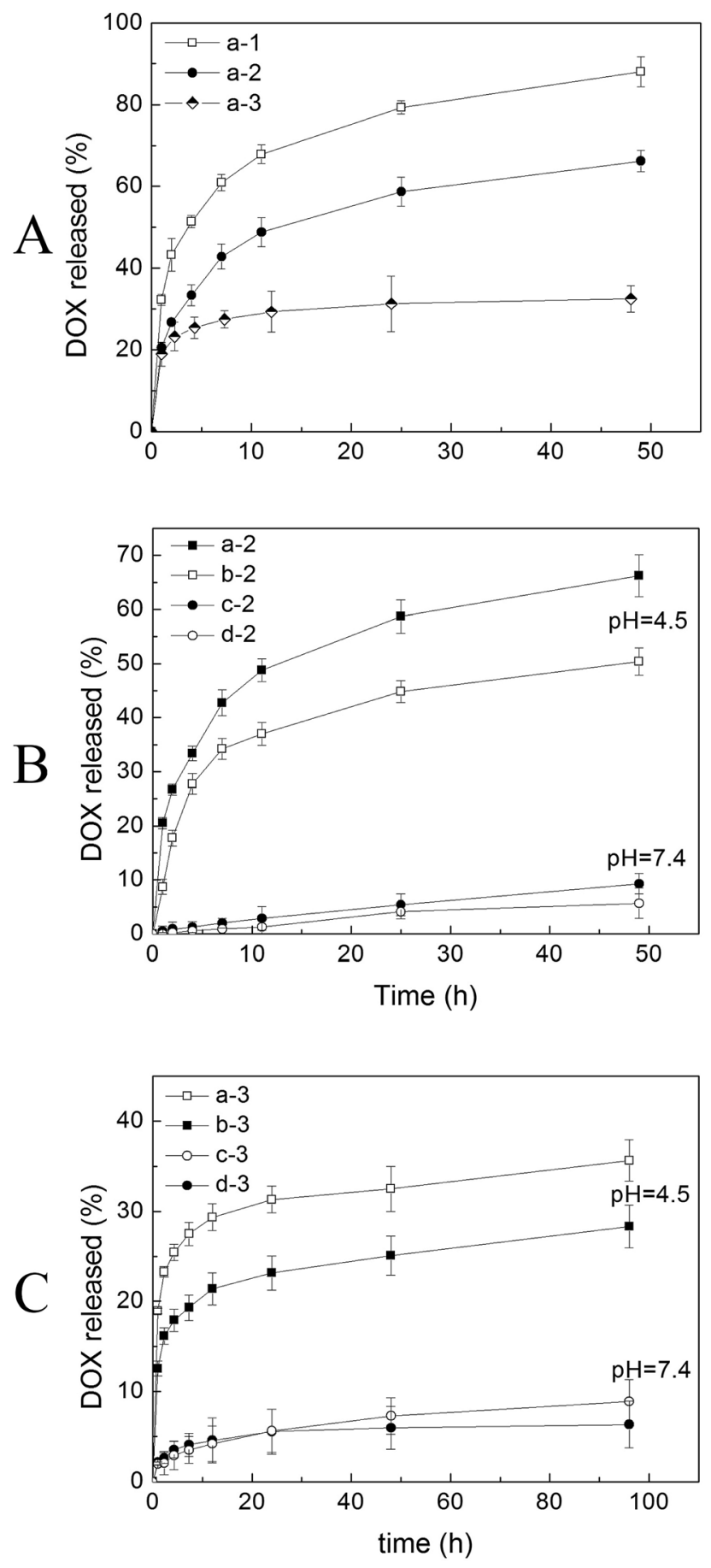

Fig. 5 (A) DOX release from MP-PNAAE, MP-PNAAEF and MPPNAAEM microgels at $\mathrm{pH} 4.5,45^{\circ} \mathrm{C}$, (a-1) DOX-loaded MP-PNAAE; (a2) DOX-loaded MP-PNAAEF; (a-3) DOX-loaded MP-PNAAEM, (B) DOX-loaded MP-PNAAEF release at different $\mathrm{pH}$ and temperature, (a2) $\mathrm{pH} 4.5,45^{\circ} \mathrm{C}$; (b-2) pH 4.5, $37^{\circ} \mathrm{C}$; (c-2) pH 7.4, $45^{\circ} \mathrm{C}$; (d-2) pH 7.4, $37{ }^{\circ} \mathrm{C}$, (C) DOX-loaded MP-PNAAEM release at different $\mathrm{pH}$ and temperature, (a-3) $\mathrm{pH} 4.5,45^{\circ} \mathrm{C}$; (b-3) $\mathrm{pH} 4.5,37{ }^{\circ} \mathrm{C}$; (c-3) $\mathrm{pH} 7.4$, $45^{\circ} \mathrm{C}$; (d-3) $\mathrm{pH} 7.4,37^{\circ} \mathrm{C}, \mathrm{pH}$ 4.5: $0.1 \mathrm{~mol} \mathrm{~L}^{-1} \mathrm{NaAc}-\mathrm{HAc} ; \mathrm{pH}$ 7.4: $0.1 \mathrm{~mol} \mathrm{~L}^{-1}$ PBS.

de-swelling state, but the MP-PNAAEM microgels are not, also demonstrating the cause of faster release rate and greater release amount.
Fig. 5B and $\mathrm{C}$ show the release curves of DOX-loaded MPPNAAEF and MP-PNAAEM under different conditions. The release curves for MP-PNAAEF and MP-PNAAEM microgels are similar to each other. As a case study for release using MPPNAAEF, the difference is found for the release of DOX from the magnetic microgels at different temperatures. At $37{ }^{\circ} \mathrm{C}$ (below LCST, Fig. 5B(b-2)), the magnetic microgels are still in a swollen state and the DOX release mainly depends on the diffusion, and thus the drug release is relatively slow. At $45{ }^{\circ} \mathrm{C}$ (above LCST, Fig. 5B(a-2)), the DOX release rate is faster than that at $37{ }^{\circ} \mathrm{C}$, and the amount of the DOX released from MPPNAAEF microgels within $48 \mathrm{~h}$ increased slightly from $50 \%$ to $66 \%$. The increased drug release at $45{ }^{\circ} \mathrm{C}$ is attributed to the collapse of the microgel. As a result, the loaded DOX was squeezed (together with water) out of the magnetic microgels.

In addition, as exhibited in Fig. 4, the release of DOX is also pH-dependent. When the $\mathrm{pH}$ value decreases to 4.5 , the DOX released from all MP-PNAAEF microgels (above 50\%) is much higher than that at $\mathrm{pH} 7.4$, both at $37{ }^{\circ} \mathrm{C}$ and $45^{\circ} \mathrm{C}$. The reasons are as follows: (1) the microgels have a smaller size at $\mathrm{pH} 4.5$, and some of the hydrogen bonds are broken, which cause the loaded DOX to be squeezed out quickly; (2) the amino group of DOX is protonated as the $-\mathrm{NH}_{3}{ }^{+}$state so that it cannot form hydrogen bonds with magnetic microgels in acidic medium, ${ }^{36}$ while the protonated DOX has a higher solubility. ${ }^{37}$ When the $\mathrm{pH}$ value decreased from 7.0 to 5.0 , the solubility of DOX dramatically increased from $0.41 \mathrm{~g} \mathrm{~L}^{-1}$ to $18 \mathrm{~g} \mathrm{~L}^{-1}$. Consequently, at $\mathrm{pH} 4.5$, the amount of drug released from MPPNAAEF increases rapidly.

In vitro cytotoxicity and cell uptake of microgels. The cellular uptake properties of carriers are important for the delivery efficiency of a drug targeted delivery system. In general, good cellular uptake of carriers usually results in an efficient drug delivery. It is known that the DOX molecule can exhibit inherent fluorescence; therefore, we can directly monitor the cellular uptake of DOX-loaded microgels by fluorescence microscopy. The cellular uptake was performed on FA-receptor-positive Hela cells $[\mathrm{FR}(+)]$ and FA-receptor-negative L02 cells $[\mathrm{FR}(-)]$. Tables 1 and 2 show the fluorescence microscopy images of cellular uptake of DOX-loaded MP-PNAAE, MP-PNAAEF and MPPNAAEM microgels at $37{ }^{\circ} \mathrm{C}$ for different times on Hela cells and L02 cells, respectively. The equivalent DOX concentration was controlled at $2 \mu \mathrm{g} \mathrm{mL} \mathrm{m}^{-1}$, and the enhanced DOX fluorescence intensity indicates an increased cellular uptake. From the fluorescence microscope images, in the first $15 \mathrm{~min}$, only a small portion of composites were uptaken by Hela cells and L02 cells. With longer incubation time, the intensity of the red signal for FA and MTHF modified microgels obviously increased on the Hela cells because the DOX-loaded carriers crossed the membrane and DOX molecules were released and localized within the cytoplasm. However, the red-emitting points of MP-PNAAE microgels were almost the same until $2 \mathrm{~h}$. On the other hand, with longer incubation time, FA and MTHF modification on the MP-PNAAE microgels had a similar intensity of red signal with MP-PNAAE microgels on L02 cells. These results corroborated that the FA-receptor-positive Hela cells may facilitate the recognition of the FA and MTHF- 
Table 1 Fluorescence microscope images of Hela cells incubated with DOX-loaded magnetic microgels ${ }^{a}$
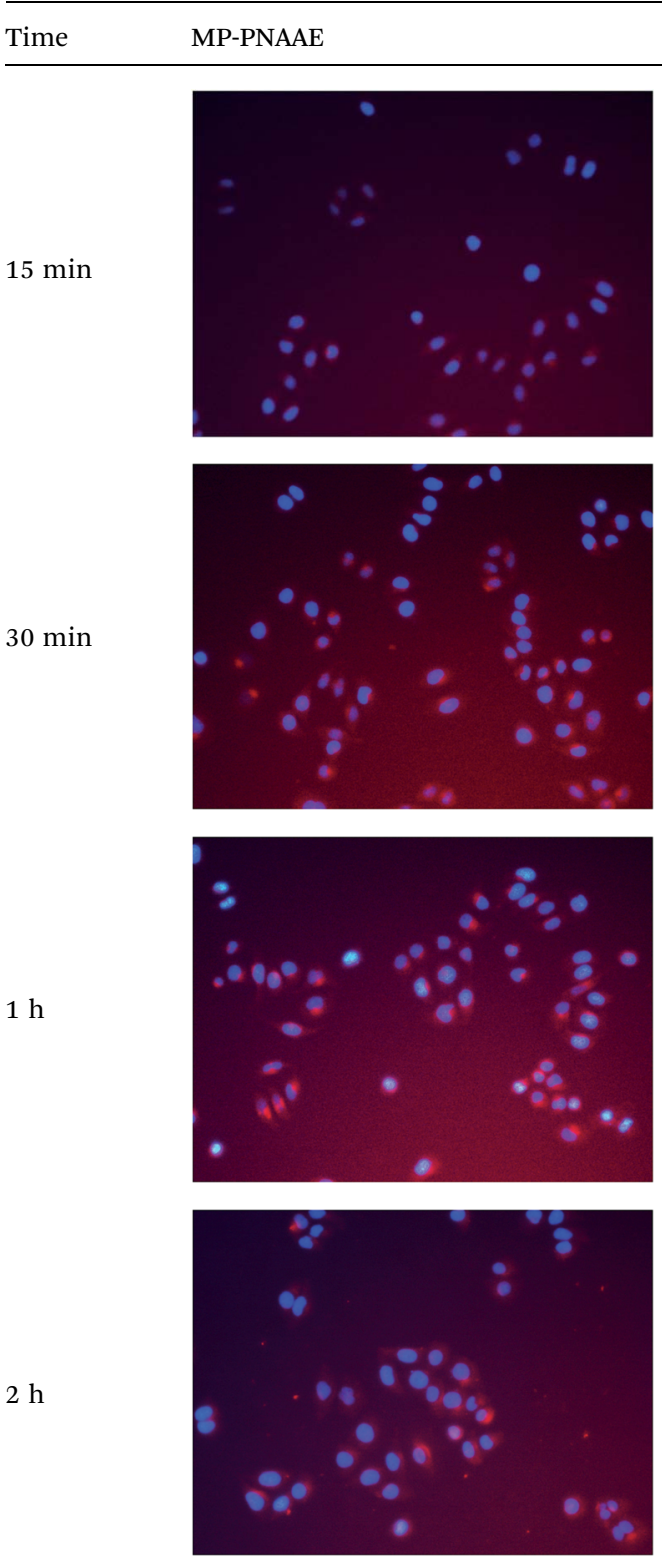

MP-PNAAEF
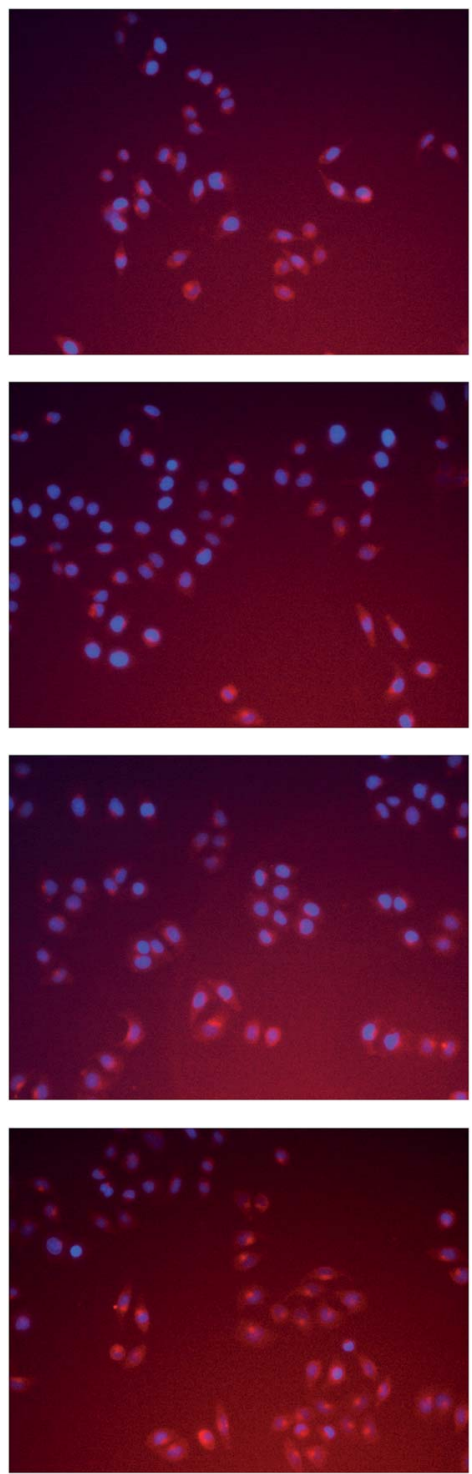

MP-PNAAEM
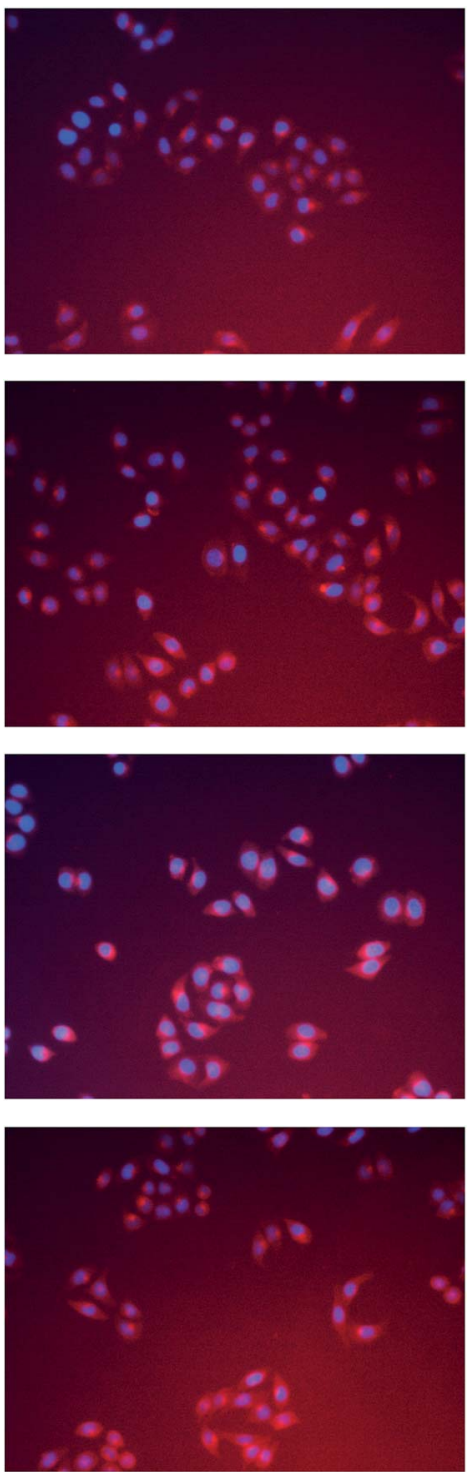

${ }^{a}$ Each series can be classified as the nuclei of cells (dyed blue with Hoechst 33324 for visualization) and the DOX-loaded microgel composite (red fluorescence); each image shows a merging of the two channels of both of the above.

modified microgels and increase the uptake through folate receptor-mediated endocytosis, which indicates that the MTHF ligand may display high affinity for the folate receptor, and could be captured from the extracellular milieu and transported inside the cell. Thus, MTHF may represent a potential ligand for targeted anticancer drug delivery.

Fig. 6A and B show the effect of bare MP-PNAAE and MPPNAAEF and MP-PNAAEM microgels on the cell viabilities of Hela cells and L02 cells measured by MTT assay. All microgels gave similar results. The difference in cell viabilities after $24 \mathrm{~h}$ of incubation was negligible, and this suggests that in the state of cellular uptake, the bare microgels had no obvious cytotoxicity to Hela cells and L02 cells. The viability after $48 \mathrm{~h}$ of incubation showed some decrease; it can be seen that the three microgels exhibit similar biocompatibility, and have little cytotoxicity up to $15 \mu \mathrm{g} \mathrm{mL}{ }^{-1}$ toward Hela cells and $30 \mu \mathrm{g} \mathrm{mL} \mathrm{m}^{-1}$ toward $\mathrm{L} 02$ cells. Comparing the DOX loading on the three microgels, the amount of DOX loaded improved for MP-PNAAEF and MPPNAAEM, indicating that for the same amount of drug, MPPNAAEF and MP-PNAAEM have lower toxicities. Therefore, FA and MTHF grafting did not decrease the biocompatibility of the microgels, suggesting that the above three microgels could be used as drug delivery vehicles.

To study the anticancer effect of the FA- and MTHFconjugated MP-PNAAE microgels and the cell inhibition of DOX solution, DOX-loaded MP-PNAAE, MP-PNAAEF and MP- 
Table 2 Fluorescence microscope images of LO2 cells incubated with DOX-loaded magnetic microgels ${ }^{a}$
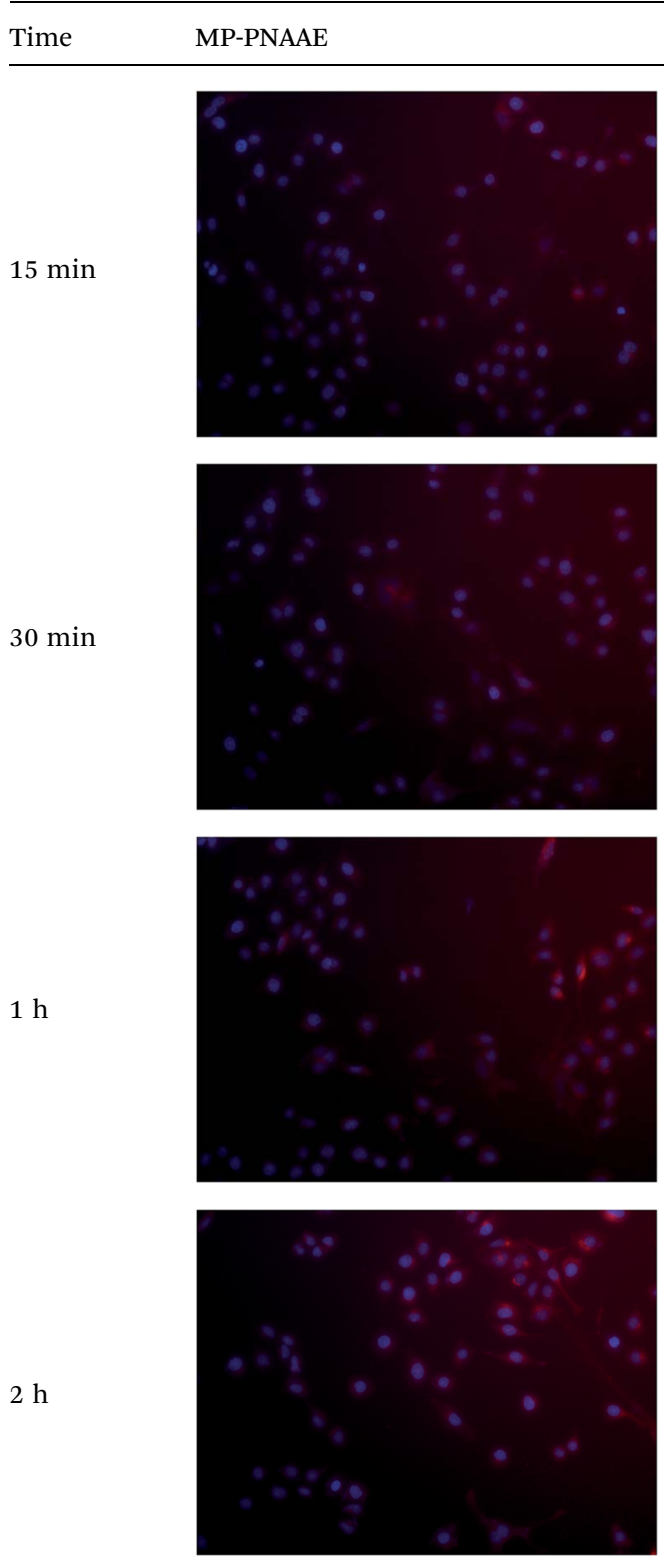

MP-PNAAEF
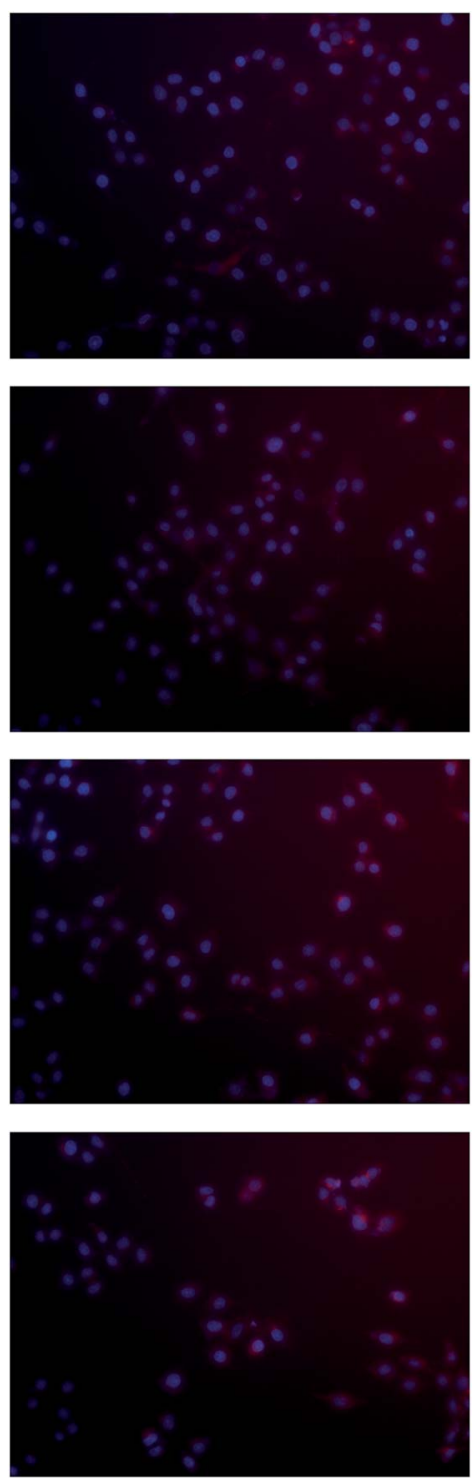

MP-PNAAEM
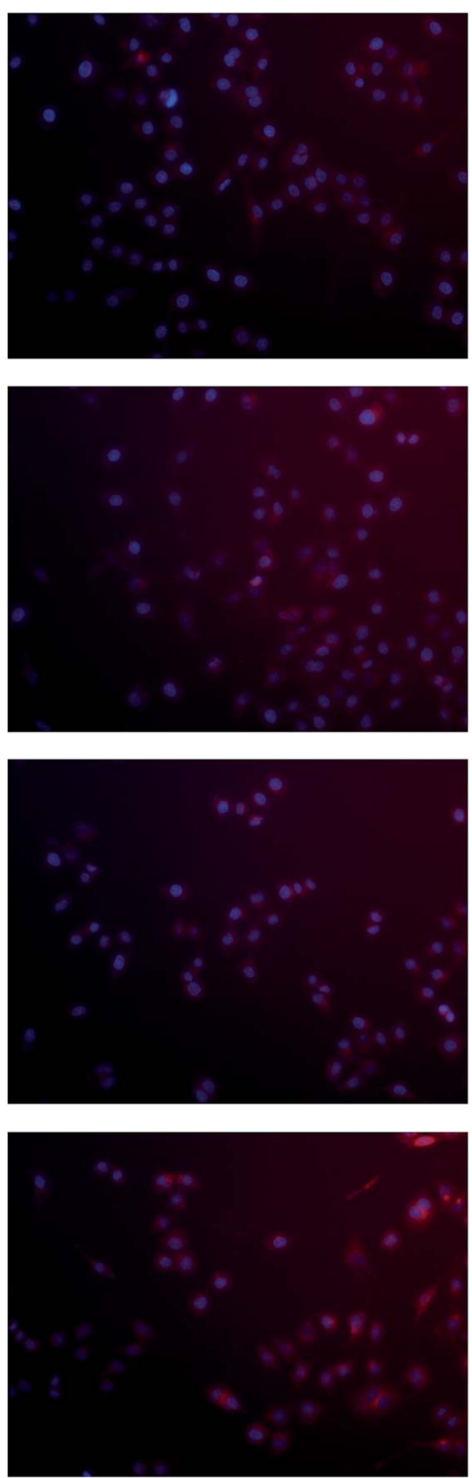

${ }^{a}$ Each series can be classified as the nuclei of cells (dyed blue with Hoechst 33324 for visualization) and the DOX-loaded microgel composite (red fluorescence); each image shows a merging of the two channels of both of the above.

PNAAEM microgels were investigated on Hela cells and L02 cells at different concentrations by MTT assays (Fig. 6C). Moreover, to verify the anticancer effect of the DOX-loaded microgels, the cell inhibition of the bare microgels was tested at different concentrations. As shown in Fig. 6A and B, the cell inhibition of empty microgels can be negligible compared to the DOX-loaded microgels. On Hela cells, Fig. 6C shows that the increased inhibition efficacy of DOX-loaded microgels occurs with the increase in their concentrations. The cytotoxic efficacies of DOX-loaded microgels are all higher than bare microgels. In addition, at the lower DOX concentration $(0.25 \mu \mathrm{g}$ $\mathrm{mL}^{-1}$ ), the DOX-loaded microgels have similar cytotoxic efficacies. With the DOX concentration increasing from $0.5 \mu \mathrm{g}$ $\mathrm{mL}^{-1}$ to $2.0 \mu \mathrm{g} \mathrm{mL}^{-1}$, the cytotoxic efficacies of DOX-loaded MPPNAAEF and DOX-loaded MP-PNAAEM microgels are all higher than free DOX and DOX-loaded PNAAE microgels, it is suggested that FA and MTHF are potentially attractive specific ligands for targeted anticancer drug delivery. As the DOX concentration increases $\left(4 \mu \mathrm{g} \mathrm{mL}^{-1}\right)$, the anticancer efficacy of DOX-loaded MP-PNAAE is even better than that of free DOX. It is well known that PEI is a cationic polymer, which has been widely used in gene delivery systems. When the positively charged PEI is conjugated on the surface of MP-PNAA microgels, the zeta potential of MP-PNAAE microgels is $38.23 \pm$ 
Hela
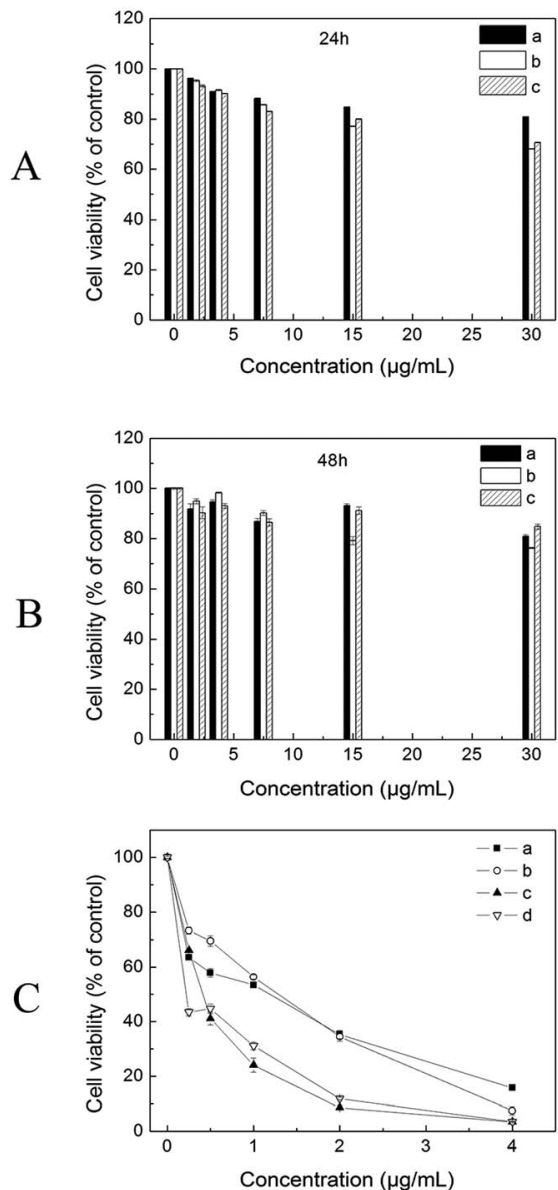

L02
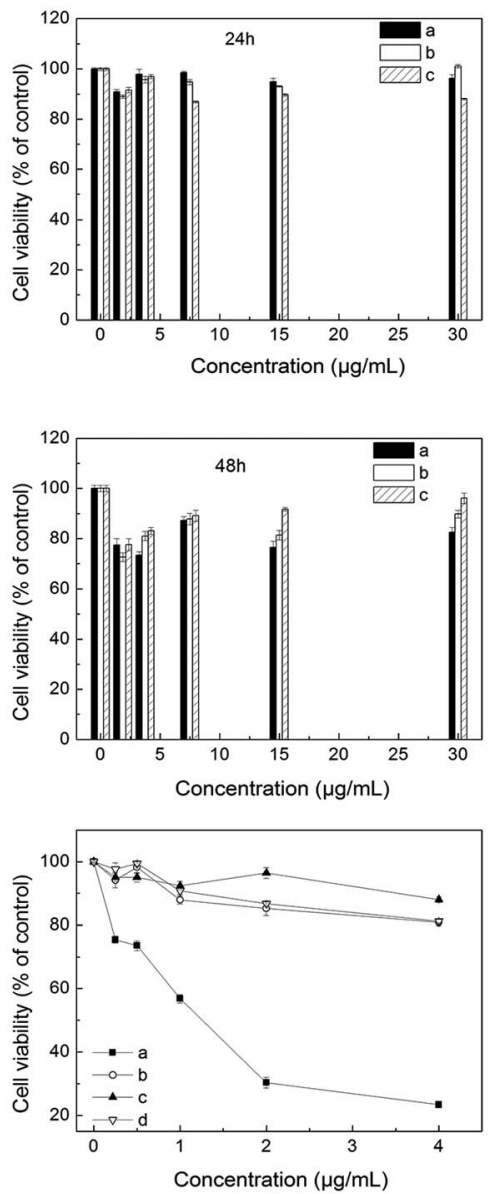

Fig. 6 (A) Cell viabilities of microgels measured by MTT assay (a) MP-PNAAE; (b) MP-PNAAEF; (c) MP-PNAAEM at 24 h. (B) Cell viabilities of microgels measured by MTT assay (a) MP-PNAAE; (b) MP-PNAAEF; (c) MP-PNAAEM at $48 \mathrm{~h}$. (C) Cell viabilities after incubation for $48 \mathrm{~h}$ with (a) DOX-loaded MP-PNAAE; (b) DOX-loaded MP-PNAAEF; (c) DOX-loaded MP-PNAAEM; (d) free DOX at different concentrations.

$1.23 \mathrm{mV}$, easily leading to binding with the negatively charged cell membrane and then moving into the endosome. ${ }^{38}$ In addition, compared with free DOX, loaded DOX molecules on MP-PNAAE microgels were partially released from the cellular internalized microgels, and resulted in less cell death. Therefore, the MP-PNAAE microgel induced drug delivery system demonstrates comparable anticancer effect to free DOX molecules. More importantly, the cytotoxicities of the FA and MTHFmodified and the unmodified DOX-loaded MP-PNAAE were similar for the L02 cells, since these cells do not overexpress the receptors.

On Hela cells, the DOX-loaded MP-PNAAEF and MPPNAAEM microgels showed much higher inhibition than free DOX and DOX-loaded MP-PNAAE, since the DOX concentration increased (greater than $0.5 \mu \mathrm{g} \mathrm{mL}{ }^{-1}$ ), and the anticancer efficacy of DOX-loaded MP-PNAAEF is a little better than that of DOX-loaded MP-PNAAEM. According to Table 1, the MPPNAAEM microgels display the same results as MP-PNAAEF microgels, suggesting that the MTHF may possess a remarkable character, having the tendency to approach the cells due to the affinity between the MTHF and folate receptor. Therefore,
Hela cells can take up more MP-PNAAEF and MP-PNAAEM microgel, which results in more DOX molecules being released in the cells, and inducing more cell death. This implies that the MTHF is a potentially attractive specific ligand for targeted anticancer drug delivery. MP-PNAAEF and MPPNAAEM microgels as anticancer drug delivery vehicles can effectively target cancer cells and enhance the anticancer efficacy.

\subsection{Conclusion}

In this paper, a targeted anticancer drug delivery system has been developed based on folate- or MTHF-conjugated thermoand pH-responsive magnetic microgels (MP-PNAAEF and MPPNAAEM) combining receptor-mediated targeting and magnetic targeting. The VPTT of the resultant magnetic microgels obviously change due to the addition of PEI and FA or MTHF monomer, and the pH-sensitivity shows that the smaller microgels were formed at $\mathrm{pH}$ 5.0, but larger particles were formed under less acidic and alkaline conditions. MP-PNAAEF and MP-PNAAEM magnetic microgels exhibit higher DOX 
loading amounts (130 $\mathrm{mg} \mathrm{g}^{-1}$ and $134 \mathrm{mg} \mathrm{g}^{-1}$, respectively) than MP-PNAAE (78 $\mathrm{mg} \mathrm{g}^{-1}$ ) under appropriate conditions. The drug release under corresponding conditions gives a sustained release pattern. The results showed that the thermo- and $\mathrm{pH}$ responsive magnetic microgels efficiently deliver anticancer drug and exhibit sustained release behaviors. On the other hand, MP-PNAAE, MP-PNAAEF and MP-PNAAEM microgels are nontoxic up to a concentration of $15 \mu \mathrm{g} \mathrm{mL} \mathrm{m}^{-1}$ on Hela cells and $30 \mu \mathrm{g} \mathrm{mL}{ }^{-1}$ on L02 cells. Although the cellular uptake of three microgels were observed with the cell lines, MP-PNAAEF and MP-PNAAEM can be specifically taken up by Hela cells via receptor-mediated endocytosis, and DOX-loaded MP-PNAAEF and MP-PNAAEM microgels exhibited greater cytotoxicity than free DOX and DOX-loaded MP-PNAAE microgels, but have similar cellular uptake for all microgels on L02 cells. It suggests that the affinity for FA receptors by MTHF is similar to folic acid; thus, MP-PNAAEM could increase the cell uptake of anticancer drug delivery vehicles mediated by the FA receptor. Therefore, both MP-PNAAEF and MP-PNAAEM have potential for targeted anticancer drug delivery for cancer therapy.

\section{Acknowledgements}

This work has been financially supported by the National Natural Science Foundation of China (No. 21472126 and No. 21672151).

\section{References}

1 X. Gu, J. J. Wang, Y. M. Wang, Y. N. Wang, H. Gao and G. L. Wu, Layer-by-layer assembled polyaspartamide nanocapsules for pH-responsive protein delivery, Colloids Surf., B, 2013, 108, 205-211.

2 Q. Q. Wang, M. Kong, Y. An, Y. Liu, J. J. Li, X. Zhou, C. Feng, J. Li, S. Y. Jiang, X. J. Cheng and X. G. Chen, Hydroxybutyl chitosan thermo-sensitive hydrogel: a potential drug delivery system, J. Mater. Sci., 2013, 48, 5614-5623.

3 H. J. Cha, J. Dai and J. C. Kim, Microgels composed of poly(ethylene imine) and carboxymethoxycoumarin: $\mathrm{pH}$ dependent and photodependent integrity, J. Appl. Polym. Sci., 2013, 129, 644-651.

4 Y. Zhu, I. Toshiyuki, H. Nobutaka and K. Stefan, Rattle-type $\mathrm{Fe}_{3} \mathrm{O}_{4} @ \mathrm{SiO}_{2}$ hollow mesoporous spheres as carriers for drug delivery, Small, 2010, 6(3), 471-478.

5 C. Rijcken, O. Soga, W. Hennink and C. V. Nostrum, Triggered destabilisation of polymeric micelles and vesicles by changing polymers polarity: an attractive tool for drug delivery, J. Controlled Release, 2007, 120, 131-148.

6 Y. Bae, W.-D. Jang, N. Nishiyama, S. Fukushima and K. Kataoka, Multifunctional polymeric micelles with folatemediated cancer cell targeting and $\mathrm{pH}$-triggered drug releasing properties for active intracellular drug delivery, Mol. BioSyst., 2005, 1, 242-250.

7 S. C. Alley, N. M. Okeley and P. D. Senter, Antibody-drug conjugates: targeted drug delivery for cancer, Curr. Opin. Chem. Biol., 2010, 14, 529-537.
8 N. Shamim, L. Hong, K. Hidajat and M. S. Uddin, Thermosensitive polymer ( $N$-isopropylacrylamide) coated nanomagnetic particles: preparation and characterization, Colloids Surf., B, 2007, 55, 51-58.

9 M. liong, J. Lu, M. Kovochich, T. Xia, S. G. Ruehm, A. E. Nel, F. Tamanoi and J. I. Zink, Multifunctional inorganic nanoparticles for imaging, targeting, and drug delivery, ACS Nano, 2008, 2, 889-896.

10 C. H. Hu, L. Zhang, D. Q. Wu, S. X. Cheng, X. Z. Zhang and R. X. Zhuo, Heparin-modified PEI encapsulated in thermosensitive hydrogels for efficient gene delivery and expression, J. Mater. Chem., 2009, 19, 3189-3197.

11 H. M. He, S. Chen, J. Z. Zhou, Y. Dou, L. Song, L. Che, X. Zhou, X. Chen, Y. Jia, J. X. Zhang, S. H. Li and X. H. Li, Cyclodextrin-derived $\mathrm{pH}$-responsive nanoparticles for delivery of paclitaxel, Biomaterials, 2013, 34, 5344-5358.

12 B. Zhang, H. Zhang, X. Fan, X. Li, D. Yin and Q. Zhang, Preparation of thermoresponsive $\mathrm{Fe}_{3} \mathrm{O}_{4} / \mathrm{P}$ (acrylic acidmethyl methacrylate- $N$-isopropylacrylamide) magnetic composite microspheres with controlled shell thickness and its releasing property for phenolphthalein, J. Colloid Interface Sci., 2013, 398, 51-58.

13 X. J. Kang, Y. L. Dai, P. A. Ma, D. M. Yang, C. X. Li, Z. Y. Hou, Z. Y. Cheng and J. Lin, Poly(acrylic acid)-modified $\mathrm{Fe}_{3} \mathrm{O}_{4}$ microspheres for magnetic-targeted and $\mathrm{pH}$-triggered anticancer drug delivery, Chem.-Eur. J., 2012, 18, 1567615682.

14 Y. Kakizawa and K. Kataoka, Block copolymer micelles for delivery of gene and related compounds, Adv. Drug Delivery Rev., 2002, 54, 203-222.

$15 \mathrm{~J}$. Sudimack and R. J. Lee, Targeted drug delivery via the folate receptor, Adv. Drug Delivery Rev., 2000, 41, 147-162.

16 F. Sonvico, S. Mornet, S. Vasseur, et al., Folate-conjugated iron oxide nanoparticles for solid tumor targeting as potential specific magnetic hyperthermia mediators: synthesis, physicochemical characterization, and in vitro experiments, Bioconjugate Chem., 2005, 16, 1181-1188.

17 J. Zhang, S. Rana, R. S. Srivastava, et al., On the chemical synthesis and drug delivery response of folate receptor activated, polyethylene glycol-functionalized magnetite nanoparticles, Acta Biomater., 2008, 4, 40-48.

18 B. Asadishad, M. Vossoughi and I. Alemzadeh, Folatereceptor-targeted delivery of doxorubicin using polyethylene glycol-functionalized gold nanoparticles, Ind. Eng. Chem. Res., 2010, 49, 1958-1963.

19 I. Slowing, J. C. Vivero-Escoto and V. Lin, Mesoporous silica nanoparticles as controlled release drug delivery and gene transfection carriers, Adv. Drug Delivery Rev., 2008, 60(11), 1278-1288.

20 J. M. Rosenholm, A. Meinander, E. Peuhu, R. Niemi, J. E. Eriksson, C. Sahlgre and M. Linden, Targeting of porous hybrid silica nanoparticles to cancer cells, ACS Nano, 2009, 3, 197-206.

21 Z. Wang, S. Chen, C. Hu, D. Cui and N. Jia, An enhanced impedance cytosensor based on folate conjugatedpolyethylenimine-carbon nanotubes for tumor targeting, Electrochem. Commun., 2013, 29, 4-7. 
22 S. J. Duthie, Folic-acid-mediated inhibition of human coloncancer cell growth, Nutrition, 2001, 17, 736-737.

23 N. Kohler, C. Sun, J. Wang and M. Zhang, Methotrexatemodified superparamagnetic nanoparticles and their intracellular uptake into human cancer cells, Langmuir, 2005, 21, 8858-8864.

24 U. Lächelt, V. Wittmann, K. Müller, D. Edinger, P. Kos, M. Hoehn and E. Wagner, Synthetic polyglutamylation of dual-functional MTX-ligands for enhanced combined cytotoxicity of poly (I: C) nanoplexes, Mol. Pharmaceutics, 2014, 11(8), 2631-2639.

25 B. A. Kamen and J. D. Caston, Properties of a folate binding protein (FBP) isolated from porcine kidney, Biochem. Pharmacol., 1986, 35, 2323-2329.

26 N. Blau, Psychomotor retardation, spastic paraplegia, cerebellar ataxia and dyskinesia associated with low 5methyltetrahydrofolate in cerebrospinal fluid: a novel neurometabolic condition responding to folinic acid substitution, Neuropediatrics, 2002, 33, 301-308.

27 Y. M. Mohan and K. E. Geckeler, Polyampholytic hydrogels: poly( $N$-isopropylacrylamide)-based stimuli-responsive networks with poly(ethyleneimine), React. Funct. Polym., 2007, 67, 144-155.

28 P. C. Griffiths, C. Alexander, R. Nilmini, S. S. Pennadam, S. M. King and R. K. Heenan, Physicochemical characterization of thermoresponsive $\operatorname{poly}(\mathrm{N}$ isopropylacrylamide)-poly(ethylene imine) graft copolymers, Biomacromolecules, 2008, 9, 1170-1178.

29 Z. C. Wang, X. D. Xu, C. S. Chen, G. R. Wang, S. X. Cheng, $\mathrm{X}$. Z. Zhang and R. X. Zhuo, In situ formation of thermosensitive P(NIPAAm-co-GMA)/PEI hydrogels, React. Funct. Polym., 2009, 69, 14-19.
30 M. Turk, S. Dincer and E. Piskin, Smart and cationic poly(NIPA)/PEI block copolymers as non-viral vectors: in vitro and in vivo transfection studies, J. Tissue Eng. Regener. Med., 2007, 1, 377-388.

31 Y. Deng, W. Yang, C. C. Wang and S. K. Fu, A novel approach for preparation of thermoresponsive polymer magnetic microspheres with core-shell structure, Adv. Mater., 2003, 15, 1729-1732.

32 T. Fan, M. Li, X. Wu, M. Li and Y. Wu, Preparation of thermoresponsive and $\mathrm{pH}$-sensitivity polymer magnetic hydrogel nanospheres as anticancer drug carriers, Colloids Surf., B, 2011, 88, 593-600.

33 L. Q. Yu, L. J. Zheng and J. X. Yang, Study of preparation and properties on magnetization and stability for ferromagnetic fluids, Mater. Chem. Phys., 2000, 66, 6-9.

34 Y. Deng, W. Yang, C. C. Wang and S. K. Fu, A novel approach for preparation of thermoresponsive polymer magnetic microspheres with core-shell structure, Adv. Mater., 2003, 15, 1729-1732.

35 W. J. Liu, R. J. Gui and Q. Guo, Study on multiresponsive magnetic microgel and release property, Journal of Donghua University, 2011, vol. 28, ch. 2, pp. 213-216.

36 X. Yang, L. Chen, B. Han, X. Yang and H. Duan, Preparation of magnetite and tumor dual-targeting hollow polymer microspheres with $\mathrm{pH}$-sensitivity for anticancer drugcarriers, Polymer, 2010, 51, 2533-2539.

37 X. Shuai, H. Ai, N. Nasongkla, S. Kim and J. Gao, Micellar carriers based on block copolymers of poly( $\varepsilon$-caprolactone) and poly(ethylene glycol) for doxorubicin delivery, $J$. Controlled Release, 2004, 98, 415-426.

38 G. Rudenko, L. Henry, K. Henderson, et al., Structure of the LDL receptor extracellular domain at endosomal pH, Science, 2002, 298, 2353-2358. 